\title{
POSSESSIVES AND RELEVANCE
}

\author{
John R. Taylor \\ Language Laboratory \\ University of the Witwatersrand
}

\section{INTRODUCTION}

In this paper I want to explore the feasibility, and some consequences, of a relevancetheoretic account of prenominal possessives in English.

A descriptively adequate account of prenominal possessive expressions (henceforth: possessives) in English needs to take cognisance of the following facts.

(a) Possessives may denote many different kinds of semantic relation between possessor and possessee: the relation may be one of ownership (John's car), kinship (John's wife), authorship (Mozart's operas), regular use (the secretary's typewriter), time (last year's drought), location (London's theatres); other possibilities include the relation of a part to a whole (the dog's tail), the relation between an event and an entity affected by the event (the ciry's destruction), the relation between an event and an agent responsible for the event (the enemy's destruction of the city), the relation between an emotional or cognitive state and the experiencer of the state (the enemy's fear, the student's knowledge); and many, many more.

(b) The number of possible semantic relations between possessor and possessee is not only very large, the number is reasonably regarded as indefinitely large. Expressions such as John's car, John's train, John's bat are subject to an openended range of possible interpretations. John's car may be the car John owns (in the legalistic sense of "own"), the car he has leased, or has rented, or borrowed, or the car he has planned to lease, rent, or borrow; or it could be the car he has designed, the car he would like to own; and so on, indefinitely.

(c) Even though the possessive may invoke many different kinds of semantic relation, there is a sense in which the relation of possession (in the legalistic 
sense of the term) does have priority, in certain contexts (Taylor 1989). (This much is implied, also, by the very term "possessive", current in English and other languages as the name of the construction.) Suppose I lend you my car (i.e. the car of which I am the legal owner), which you then crash. You may report the accident to a passer-by, whom you approach for assistance, with the statement I've just crashed my car. Here, my car has the sense "The car I happened to be driving". But you could not come to me and tell me that you have just crashed "your car". In this situation, the car that you have crashed is clearly my car, not your car!

(d) In spite of the open-endedness of possessive relations, the possessive construction is not compatible with any semantic relation. Symptomatic is the fact that the two nominals in a possessive construction may not normally be reversed. The possessor may designate a whole, of which the possessee is a part (the dog's tail); on the other hand, the part may not "possess" the whole (*?the tail's dog). We may have the relation between a participant in an event and the event itself (the plane's departure), but the event may not function as the "possessor" of the participant ("the departure's plane).

(e) There are some very striking differences amongst possessives with respect to the range of possible interpretations. As noted, some possessives, like John's car, are open to a potentially indefinite range of interpretations. For other expressions, the range of possible interpretations is very strictly circumscribed. John's wife can only denote the woman related to John by marriage; the expression could not denote a married woman who bears any relation of association to John. "The married daughter of John", or "the married woman with whom John is currently having a casual affair", for example, do not constitute possible interpretations of John's wife.

(f) With respect to possessives whose interpretation is highly determinate, special problems are raised by those expressions whose possessee is a noun derived from a transitive verb, and whose possessor is interpreted as an argument to the nominalised predicate. At least since Chomsky (1970), the proper treatment of such expressions has been a major issue in formal syntax. There is insufficient space here to detail the facts in all their complexity. Mention should be made, however, of two descriptive generalisations which to this day continue to inform the theoretical discussions. These are the Affectedness Constraint, due to Anderson (1978), and the Experiencer Constraint, due to Rappaport (1983). 
The Affectedness Constraint pertains to possessives with an "objective" reading. According to the Affectedness Constraint, a nominal whose referent is "unaffected" by the process designated by a derived noun is banned from functioning as possessor to the derived noun. The Affectedness Constraint predicts the impossibility of *the cliff's avoidance (by the hikers), in contrast to the acceptability of the city's destruction (by the enemy). The Experiencer Constraint pertains to possessives headed by nouns which denote a cognitive or emotional state. In such expressions, the possessor may readily express the experiencer of the state, but not the entity that causes, or is the object of the state. The enemy's fear thus denotes the fear felt by the enemy, not the fear which is felt towards the enemy.

(g) Many possessives are open to alternative wordings, notably by means of a postnominal of-phrase. Alongside the city's destruction we have the destruction of the city. Yet not all prenominal possessives permit an of-wording; conversely, not all postnominal of-expressions permit a prenominal possessive wording. Furthermore, even when both possibilities are available, the two wordings may not be truth-conditionally equivalent. Yesterday's news, in the sense "news that was reported yesterday", need not be news of yesterday, i.e. "news concerning events that happened yesterday". The fear of the enemy could denote the emotion that is felt towards the enemy, a meaning which, as already noted, is not available for the enemy's fear.

My main concern will be with (a) - (f). A full discussion of (g) would go beyond the more modest aims of the present paper, in that a comparison of the prenominal possessive with the postnominal of-construction presupposes a prior analysis of both constructions.

\section{POSSESSIVES IN RELEVANCE THEORY}

In the course of their presentation of relevance theory, Sperber \& Wilson (1986:188) briefly touch on the semantics of the possessive construction. They reject the notion that the possessive construction could be multiply polysemous, "with as many senses as there are types of relationship it may be used to denote". Their reasons appear to be twofold. Firstly, possessives are not generally felt to be ambiguous. Their second 
reason has to do with the very open-endedness of possessive relations; whereas multiple polysemy might in principle be tolerable, indefinite polysemy certainly is not.

Sperber \& Wilson also reject a "common core" approach to the possessive, i.e. the notion that "all these [possessive] relationships fall under a single definition which is the only meaning expressed by use of the genitive [= possessive: JRT] on any given occasion". Rather, they prefer to regard the construction as semantically vague, or underdetermined. "Contextual information is needed to resolve what should be seen as the semantic incompleteness, rather than the ambiguity, of the genitive".

The three possibilities entertained by Sperber \& Wilson - viz. the "polysemy" of the possessive construction, the possibility of a "common semantic core", and the claim that possessives are "semantically incomplete" - are not per se incompatible, or mutually exclusive. The possessive construction may well be "semantically incomplete", but it is certainly not semantically empty. The non-reversibility of possessives, noted in section 1 , as well as the severe restrictions imposed by the Affectedness and Experiencer Constraints, suggest, in fact, that the possessive construction might well be constrained by a quite specific semantic content. If this is correct, the possibility exists that this semantic content may be shared by all instantiations of the construction. Such a state of affairs is not inconsistent with the possibility that the common semantic core could be subject to elaboration, or "enrichment", depending on a range of contextual factors, including the identity of the nominals functioning as possessor and possessee. Neither is the notion of an underdetermined semantic core in itself incompatible with polysemy. According to Langacker's "network model" of category structure (Langacker 1988), a semantic representation, underdetermined with respect to a range of specific details, may well coexist with a range of specific instantiations of the schema.

Our first task, therefore, must be to identify the semantic content of the possessive construction. Sinclair \& Winckler (1991:28) have suggested "somehow associated with" as the general meaning of the possessive morpheme. For reasons touched on in the above paragraph, this suggestion must be rejected. Given sufficient ingenuity, just about anything can be "somehow" associated with just about anything else. Yet it is manifestly not the case that any randomly selected pair of nominals may be adjoined in the possessive construction in virtue of the fact that some relation of association may exist between the referents of the nominals. And even when the nature of the semantic relation between two nominals is perfectly transparent, this fact does not of itself guarantee the acceptability of a possessive expression. Witness the unacceptability of 
the cliff's avoidance, the impossibility of an objective reading of the enemy's fear, and the utter bizarreness of the departure's plane.

In the following section, rather than attempt to circumscribe (or to taxonomise) the kinds of semantic relation that may hold between possessor and possessee, I suggest that the essence of the possessive construction lies in the pragmatic function of the possessor phrase. A more ambitious claim, developed in sections 4 and 5 , is that the pragmatic account alone may be sufficient to explain the full range of semantic and syntactic properties of possessive expressions.

\section{THE SEMANTICS OF THE POSSESSIVE}

Traditional theories of syntax assign to possessive expressions the structure [NP[DET NP POSS] [N']]. A possessive expression, in other words, constitutes an NP, headed by the possessee (an $\mathrm{N}^{\prime}$ ), whose determiner consists of an NP (the "possessor") in association with the possessive morpheme POSS.

Possessives almost invariably have definite reference. That is to say, in using a possessive expression, a speaker conveys, firstly, that she has singled out, from the category of entities denoted by the possessee noun, a unique referent; the speaker conveys, secondly, that she presumes that the hearer, also, is in a position to uniquely identify the intended referent. Crucial to the semantics of the construction is the question how the determiner phrase [NP POSS] confers the property of definiteness of the possessive expression.

Consider, first, the broader question of how a speaker can in general be assured of the hearer's ability to uniquely identify the intended referent. There are various possibilities. The intended referent may be unique within the context of situation, including the context provided by prior discourse (light the fire, close the door, answer the question). The speaker may make an ostensive gesture towards the intended referent (this man over here, that cat over there). A further possibility is that the NP itself may contain information which guarantees (or which the speaker presumes will guarantee, or at least facilitate) the referent's identification. For example, the NP may contain a postnominal adjunct phrase which serves to delimit the referential possibilities of the headnoun (the people who live next door, the car I was driving, the day I was born). 
The possessive construction provides the English speaker with a rather special device for facilitating referent identification by the hearer. The account that I propose is based on Langacker's "reference point" analysis of the construction (Langacker 1991:169ff.; to appear). Langacker observes that when we conceptualise, or "establish mental contact with", an entity, we frequently do so via the prior conceptualisation of another entity. The one object thus serves as a "reference point", i.e. it provides the necessary background context, for the conceptualisation of the target. For example, a part typically requires, for its conceptualisation, a notion of the whole to which the part belongs. The whole may thus serve as a reference point for the conceptualisation of the part. And to designate an entity by means of a relational noun, such as wife, friend, employer, enemy, etc., typically presupposes some notion, however vague and underdetermined, of the relatum to which the designated entity bears the appropriate kind of relation. Again, the relatum may serve as reference point for the identification of the designatum.

On Langacker's analysis, the possessor nominal names such a reference point entity, which gives the context for the conceptualisation of the target entity. The import of the possessor phrase is thus to make explicit the mental path that the hearer must follow in order to identify the target. Slightly elaborating on Langacker's analysis, we may say that in opting to use a possessive construction, the speaker is instructing the hearer on how best to identify the referent intended by the speaker. The speaker, that is, invites the hearer to first conceptualise the one entity (the "possessor"), with the guarantee that this will facilitate identification of the target entity.

In support of the reference point account, it is worth drawing attention to the rather self-evident (but nevertheless, in the formal syntactic literature almost universally overlooked) fact that in the English possessive construction the possessor NP is mentioned before the possessee. The fact is important in that, if a concept is to discharge its reference point function, it is only natural that the concept should be mentioned before the target entity. And with respect to constituent order, the English possessive construction differs crucially from possessive constructions in many other languages. In Romance, Slavic, Bantu, and the inflecting Germanic languages, the possessor is named after the possessee, e.g. in a postnominal prepositional phrase, or in a genitive-case adjunct nominal. It should not be too surprising, therefore, if the distribution of the prenominal possessive construction in English should not correspond exactly with the distribution of possessive constructions in other languages (or, for that matter, with the postnominal of-construction in English). 
The reference point account of the possessive construction is broadly compatible with relevance theory. Sperber \& Wilson (1986:202ff.) suggest that certain elements of the surface form of an utterance - such as topicalisation, dislocation, clefting, and the location of tonic prominence - make no contribution to the propositional content coded by the utterance, but rather function as processing cues to the hearer. These aspects of an utterance, namely, point the hearer towards the recovery of certain pragmatic effects, in preference to others. Admittedly, [NP POSS], i.e. the determiner phrase to a possessive expression, is not strictly comparable with these "stylistic" phenomena. While the expressions John's wife, Jill's daughter, Fred's mother, and my colleague could each denote one and the same individual, the expressions are clearly not truthconditionally equivalent; the possessor phrase therefore does make some contribution to the propositional content of the utterance in which it occurs. Nevertheless, a speaker's choice of one of these expressions as a means of designating a specific individual is surely motivated by the speaker's assessment of the hearer's current state of knowledge, and by her assumptions concerning the most effective means of getting the hearer to uniquely identify the intended referent. If the speaker has reason to believe that the hearer is acquainted with the intended referent, and knows the referent by the name of Mary, it will be sufficient to designate the referent by the name Mary. Failing this, the intended referent may be designated via some individual presumed to be known to the hearer. For example, if the speaker presumes that the hearer is familiar with the referent's husband, John, and presumes that the hearer knows that the husband bears the name John, the speaker can achieve her communicative goal by means of the possessive construction John's wife.

\section{CHARACTERISTICS OF THE POSSESSOR}

The adequacy of the above account of the possessive construction must be measured against its success in accounting for the range of data that was surveyed in section 1.

Let us make a start by considering the implications for the choice of possessor nominal. I suggest that two requirements, largely independent of each other, on possessor nominals fall out rather naturally from the above account. These concern the topicworthiness of the possessor nominal, and the informativity, or cue validity of the possessor nominal vis-à-vis the referent of the possessee noun. 


\section{(a) Topicworthiness}

Admittedly, topicworthiness is a tricky notion to pin down. However, following work by Givón (1983), Chafe (1987), Deane (1987), and others, we may characterise topicworthiness in terms of the cognitive salience, or accessibility, of a concept. With respect to the possessive construction, we would expect that the more accessible a concept is to a hearer, the more readily that concept is able to discharge a reference point function.

We may distinguish two dimensions of topicworthiness. On the one hand, a concept that is already in a person's focus of awareness is going to be more topical than a concept which must be first retrieved from memory. Topicworthiness, therefore, is a function of preceding discourse; entities that have already been introduced into a discourse, and which have been mentioned in immediately preceding discourse, will be readily available to function as reference points.

In addition to discourse-conditioned topicworthiness, we may also recognise degrees of "inherent topicworthiness". The idea is that certain concepts, by their very nature, are $\stackrel{\circ}{\circ}$ more readily accessible, or retrievable, than others. We may thus propose a "hierarchy of topicworthiness", according to which humans are more topicworthy than nonhumans, animates more topicworthy that inanimates, concretes more topicworthy than abstracts, definites more topicworthy than indefinites, and so on.

The topicality thesis was amply confirmed in a text-based study reported in Taylor (1991). The possessor nominals in the data base overwhelmingly exhibited a cluster of properties traditionally associated with topicworthiness. The nominals, that is, turned out to be overwhelmingly animate, definite, and pronominal, and their referents were of recent mention in preceding discourse. It is also worth noting that the topicality hierarchy is implicit in many traditional accounts of the possessive construction. Especially pedagogical grammars have noted that the possessive construction "works best" if the possessor is human.

Particularly intriguing is the possibility that topicworthiness may motivate some of the constraints on possessors that have been proposed in the formal literature. Consider the Experiencer Constraint. An animate, and typically human experiencer of an emotional or cognitive state is going to display a higher degree of inherent topicworthiness than the often inanimate, or even abstract entity that causes, or is the object of, the 
emotional or cognitive state. The topicality hypothesis thus predicts that an experiencer can more readily function as a possessor than the entity that is experienced.

Furthermore, some attested violations of the Experiencer and Affectedness Constraints appear to be sanctioned by the discourse-conditioned topicality of the possessor. Considered in isolation, the expressions music's pursuit and the statue's impression would no doubt be judged ungrammatical. The former violates the Affectedness Constraint, in that music is in no way "affected" by its being pursued; the latter violates the Experiencer Constraint, in that the statue is the cause, not the experiencer, of the impression. Consider, now, the following examples, culled from the LOB (= Lancaster-Oslo-Bergen) corpus.

(1) Men with the greatest insight into music use one life in its pursuit and lack another in which to command words in a way that effectively communicates their musical judgement.

(2) ... his statue of a man with a child on his shoulders, whose first impression of brute strength yields to a sense of uncertain architecture and even pretentiousness.

Note that in each case, the possessor entity - "music" and "statue", respectively - has been rendered topical by preceding discourse.

\section{(b) Informativity}

Topicworthiness is clearly not the only factor which influences the acceptability of a possessive expression. Compare the ciry's destruction and *the cliff's avoidance. Arguably, the city and the cliff do not differ substantially in inherent topicworthiness. Yet the former is readily acceptable, the latter is not. Or consider the fact that Herbie's love can only have an experiencer, or "subjective" reading; Herbie can only be the person who loves, not the person who is loved. No amount of contextual manipulation, it would seem, is able to alter these basic intuitions.

In terms of the account of the possessive construction being pursued here, we need to say that an affected entity can more readily function as a reference point for the subsequent identification of an event than can a non-affected entity. Likewise, the 
experiencer of an emotional or cognitive state can more readily function as the reference point for the subsequent identification of the state than can the object, or source, of the state.

Let us call this aspect of a reference point entity its cue validity vis-à-vis the target entity. Cue validity is the converse of informativity. That is to say, $R$ has cue validity with respect to the identification of $T$ to the extent that a conceptualisation of $T$ permits informative inferences to be drawn with respect to $R$.

\section{Consider a psychological predicate like love. Love denotes a relation between two entities, one that loves and one that is loved. In terms of the above characterisation, love is clearly more informative with respect to the entity that loves than with respect to the entity that is loved. Given a schematic sentence of the form $X$ loves $Y$, we may infer quite a lot about $X$, e.g. that $X$ is a sentient animate creature, prototypically a human being; also that $X$ is in a significant emotional state. Concerning $Y$ we can infer practically nothing. $Y$ may belong to practically any ontological category; we can say nothing about the present state, or condition, of $Y$; we may not even infer the real-world existence of $Y$, since the object of $X^{\prime} s$ love could well be a figment of $X^{\prime} s$ imagination.}

The importance of the related notions of cue validity and informativity can be illustrated from another perspective. Suppose we are told that Herbie loves Louise. Suppose, further, that we wished to ascertain the truth value of this statement. How would we go about it? Where, in other words, would we look in order to find out whether the stated relation between Herbie and Louise does, in fact, hold? Rather obviously, we would look to the entity with greater cue validity/informativity, i.e. we would tum to Herbie, and enquire about his emotional state. There would be little point in turning to Louise; for one thing, the Louise that Herbie is said to love might exist only in the imagination of Herbie. The significance of this example to the semantics of the possessive construction should be evident. In both cases we are concerned with singling out a relation for our conscious attention. And in both cases we do so via attention to a participant which has greater cue validity vis-à-vis the relation.

Let us turn, now, to the contrast between the city's destruction and *the cliff's avoidance. Applying the same kind of reasoning as above, we can easily see that an affected entity has greater cue validity, and is therefore more suited to the reference point function, than a non-affected entity. Given that $X$ destroyed $Y$, we may draw 
some quite specific inferences about $Y$. We infer that $Y$ has undergone a verry substantial change in state, such that previous to the event $Y$ was a structured whole, while subsequent to the event it is possible that the referent of $Y$ may no longer even be appropriately categorised as a "Y". Given that $X$ avoided $Y$ we can say little about $Y$ and the little that we can say must be expressed in terms of the perceptions of $X, \mathrm{e} . \mathrm{g}$. that $X$ perceived $Y$ to be an obstacle, or hindrance of some kind. Accordingly, were we to attempt to assign a truth value to the proposition that the hikers avoided the cliff, there would be little point in examining the cliff, to see whether it has been avoided. A cliff that has been avoided looks no different than a cliff that has not been avoided; the cliff, therefore, has zero cue validity for an identification of an act of avoidance. On the other hand, to ascertain whether the enemy destroyed the city, our first impulse would surely be to examine the referent of the city, for visible signs that it had been destroyed. The entity that is claimed to have been destroyed therefore has very great cue validity for the identification of an act of destruction.

\section{THE RELEVANCE OF THE POSSESSOR}

The principle of informativity, or cue validity, was worked out in an attempt to offer a semantic/pragmatic explanation of the Affectedness and Experiencer Constraints (Taylor, to appear).

With little modification, the principle can also be invoked in connection with the highly determinate interpretation of John's wife, and similar expressions headed by relational nouns, perhaps also for possessives denoting a whole-part relation. The very fact that a person comes to be designated by a relational noun such as wife, rather than by a nonrelational noun such as woman, entails the existence of a relatum, in this case another person, i.e. the husband, to whom the designated person bears a certain kind of kinship relation. Specific inferences can be drawn with respect to the relatum, with the consequence that the name of the relatum (i.e. the husband) has high cue validity for the identification of the target (i.e. the wife). - In comparison, all other entities with which the designated person may have some or other relation of association have minimal, or insignificant cue validity. Likewise, the notion of a part, especially a part which typically has no independent existence except as a constituent of a whole, entails the notion of the whole; the name of the whole therefore has high cue validity for the identification of the part. On the other hand, the name of a part has minimal cue validity for the identification of the whole. A whole typically consists of many, 
perhaps even an indefinite number of parts; no one part has privileged status as the relatum of the whole; indeed, nouns designating wholes would not normally be considered to be relational nouns at all.

In relevance theoretic terms, one would say that John's wife has the interpretation that it has in virtue of the relevance of this interpretation: Sperber \& Wilson (1986:125) characterise relevance in terms of (a) the maximisation of "contextual effects", i.e. inferences, relative to a context, and (b) the minimisation of processing effort, relative - to the context. On the one hand, the standard interpretation of John's wife gives rise to ontrivial contextual effects; the hearer infers that the designated person bears a specific kind of kinship relation to a known individual, i.e. John. Secondly, the hearer achieves this contextual effect with minimal processing effort. Note, however, that the - processing of John's wife does not require the hearer to access background, or 흘 contextual information. The hearer's assumptions about the known individual "John", or about the intended referent of wife, or indeed about anything else in the world, play absolutely no rol: whatsoever in the interpretation of John's wife. Rather, processing takes place, quite simply, in virtue of the hearer's knowledge of what it means for a person to be designated by the word wife, i.e. in virtue of the hearer's knowledge of the semantic structure of the word wife.

In contrast to John's wife, Herbie's love, the city's destruction, and so on, which have only a single and highly determinate interpretation, many possessive expressions are open to a wide range of readings. The distinguishing feature of these expressions is that they are headed by nonrelational nouns, more precisely, by nouns that designate what Langacker (1991:286ff.) calls conceptually autonomous entities. An entity is conceptually autonomous to the extent that it is possible to conceptualise that entity without making necessary or intrinsic reference to anything outside the entity itself. The concepts "wife", "love"., "destruction" are conceptually dependent, in that one can only conceptualise "wife", for example, by making reference to the relatum in virtue of which a person comes to be categorised as a wife in the first place. While conceptually autonomous entities - such as "car", "train", "(cricket) bat" - are known to participate in all kinds of relations (cars are driven by drivers, trains convey passengers, cricket bats are used for hitting cricket balls), our conception of "car", "train", "bat" is still coherent independently of such knowledge. Consequently, conceptually autonomous entities are not associated with any natural, or optimally relevant reference points. 
How, then, are expressions of the kind John's car, John's train, John's bat, interpreted?

According to the account of the possessive proposed in section 4, a speaker, in using a possessive expression, intends the hearer to identify the referent of the possessee nominal. To achieve this purpose, she first names a reference point entity, the possessor, which she presumes the hearer is already able to identify, as a cue for the subsequent identification of the possessee. Since the semantic structure of the possessee nominal does not suggest an optimally relevant interpretation, the hearer processes the expression against his assumptions concerning the possessor, and the most relevant relation, in the context, that may link the possessor and the possessee. Suppose John is known to have achieved a certain reputation as a car designer. On being shown a photograph of "John's latest car", a hearer could reasonably presume that the car in question is one that John has designed. Alternatively, in a situation in which the employees of a car-hire company are allocating cars to clients, a hearer could reasonably presume that John's car refers to the car that is to be rented to John.

The above interpretations exemplify the standard operation of relevance theory, whereby expressions are processed against contextual assumptions with a view to maximising relevance. But there is one further fact about possessive expressions that still needs to be accounted for, namely the priority, in many contexts, of the possession relation. I suggest that the possession relation represents the default interpretation. Given an expression like John's car, where (a) the possessor nominal names a human being (this is in any case the statistical norm; as suggested by Taylor (1991), the overwhelming majority of possessor nominals do denote humans); (b) the possessee nominal names a conceptually autonomous entity, which is therefore not associated with any natural reference point; and (c) the hearer fails to access contextual assumptions which might make it possible to infer a specific semantic relation between the possessor and the possessee - in such a situation the hearer falls back on the default strategy, i.e. the relation is interpreted as one of possession.

Several features render the possession interpretation especially appropriate as the default option. For example, any object prototypically has only one owner. If a car is my car, i.e. the car that I own, then, barring joint or communal ownership, the car cannot simultaneously be your car. The uniqueness of the possession relation is therefore highly consistent with the function of the possessive construction, i.e. as a means for uniquely identifying the possessee referent, given a uniquely identified reference point. 
A special challenge to Relevance Theory would be to explicate those contexts in which the possession relation overrides other interpretations. For example, whenever possessor nominals are used contrastively, the possession relation tends to predominate. Whereas his car, in John was driving his car, can have an indefinite number of interpretations, a statement to the effect that John was driving HIS car, not YOUR car very strongly invokes possession, to the exclusion of all other possibilities.

\section{CONCLUDING REMARKS}

In recent years, relevance theory has been applied to the description of various kinds of syntactic phenomena, such as the will vs. be going to future forms (Haegeman 1989), conditionals (Smith \& Smith 1988), and anaphora (Kempson 1988). The present study suggests a further area of application.

Ironically, the extension of relevance theory to syntactic phenomena may not be without problems for the theory. As emphasised by Wilson \& Sperber (1986), relevance theory is predicated upon a clean distinction between a person's grammatical competence and a person's more general cognitive and inferential skills. Grammatical competence enables a person to assign a semantic representation to an utterance. Relevance theory is an attempt to explicate the principles whereby a hearer goes beyond the grammatically encoded meaning to derive a speaker's intended meaning(s). In a very important sense, therefore, relevance theory only takes over after the grammar has done its job.

More than this, Wilson and Sperber assign different cognitive status to grammatical competence on the one hand, and to pragmatic skills on the other. They (1986:67) even go so far as to claim that grammar and pragmatics - apart from the trivial fact that both involve mental activity, and both involve language (the grammar, necessarily, and pragmatics, circumstantially) - have nothing substantive in common.

In the spirit of Fodor (1983), it is claimed that a person's grammatical competence constitutes a peripheral, special-purpose module of the mind. Like other peripheral systems, such as vision, the grammatical module operates rapidly and automatically, according to genetically determined mechanisms which are unique to the module in question. The grammatical module is informationally encapsulated, i.e. grammatical 
processing can make no reference to anything outside the grammar. As mentioned, the output of the grammatical module is a (possibly incomplete) semantic representation, which is then submitted to the central processing system. Central thought processes, in contrast to the input modules, may draw on all kinds of information, i.e. they have access not only to information from input modules, but also to the vast store of encyclopedic knowledge residing in memory. Central thought processes operate by non-demonstrative inference; their output is subject to revision; and their operation may be slow and even subject to conscious introspection.

To the extent that phenomena pertaining to the grammaticality of a sentence become amenable to a pragmatic explanation, the boundary between the grammar and pragmatics, between the informationally encapsulated input module and the central processing strategies, is liable to become blurred. Now, the fact that tense and aspect may be subject to relevance theoretic principles probably has no serious implications for the autonomy of syntax. After all, the cited works by Haegeman (1989) and Smith \& Smith (1988) are concerned, essentially, with matters of semantic interpretation, rather than with formal syntactic issues. To the extent that anaphora has been regarded, at least in Chomskyan linguistics, as a "core" syntactic phenomenon, a pragmatic account of anaphora, such as Kempson (1988) proposes, is a more serious threat to the thesis of the informational encapsulation of the grammar. On the other hand, there would seem to be no a priori reason why one should not suppose that the problem of anaphora, too, pertains essentially to strategies of pragmatic interpretation, rather than to formal constraints on grammaticality, in that an utterance of an anaphoric expression invites the hearer to search for the most likely antecedent; if no suitable antecedent can be found, the utterance is rejected as semantically uninterpretable. It is interesting to note, however, that Kempson is led to propose some modest interaction between pragmatics and grammar. She (1988:429) suggests, namely, that the "semantic interpretation" of a sentence is not a purely linguistic (i.e. informationally encapsulated) entity after all, but is constrained also by pragmatic principles, i.e. by "the logic of the central cognitive mechanism".

A pragmatic account of possessives makes further inroads into the alleged autonomy of the grammatical module. At least a substantial subclass of possessive expressions namely, those headed by derived, especially deverbal nouns - have certainly been regarded by generative linguistics as a central and legitimate object of formal investigation. If the approach outlined in the preceding pages is on the right track, then these expressions, also, become subject to the operation of central cognitive processes. (The reader may also have noticed that the discussion in sections 4 and 5 presupposes a 
rather broad, encyclopedic conception of word meaning; such a possibility would be precluded on Kempson's (1988:429) assumption that syntactic rules, "as induced from lexical representations, have no access to other cognitive mechanisms".) Indeed, as more and more syntactic phenomena are shown to be motivated by pragmatic principles, the thesis of the informational encapsulation of the grammatical module becomes increasingly suspect. To the extent that relevance theory presupposes the autonomy of the grammatical module, relevance theory itself, as presented by Sperber $\&$ Wilson, may also need to be reevaluated. The very success of relevance theory may weaken the foundations on which the theory is built. 


\section{NOTES}

1. Developmentally, the "possession" relation appears to have priority. See Brown (1973:233).

2. Some of the landmarks in generative treatments of prenominal possessives are Jaeggli (1986), Safir (1987), Zubizarreta (1987), Grimshaw (1990), and Giorgi and Longobardi (1991).

3. That is to say, the possessor nominal bears a semantic relation to the deverbal noun analogous to that of the direct object to the base verb.

4. For some suggestions, see Taylor (to appear). For an analysis of ofexpressions, see Langacker (1992).

5. A taxonomy of possessive relations is offered in Quirk et al. (1985:321f.). More sophisticated taxonomies are presented in Taylor (1989) and Nikiforidou (1991).

6. The qualification is necessary, because some recent versions of X-bar syntax have rechristened the traditional NP as a DP (= determiner phrase), headed by $\mathrm{D}$ (= determiner), while the traditional $\mathrm{N}^{\prime}$ has become the NP complement of D. On this account a possessive is headed by POSS, the possessor nominal is the specifier of $\mathrm{D}$, and the possessee its NP complement. Note also that on this account the "possessor phrase", i.e. [NP POSS], no longer has the status of a constituent.

7. The hedge "almost invariably" is necessary, in that possessives may occasionally have nondefinite reference. Langacker (1991:168) cites the following example, where the speaker's wish would be fulfilled if any car, of any teenager, participated:

(i) I want some teenager's car to enter in a demolition derby.

The need for the hedge in itself points to the correctness of the pragmatic account being presented here, in that pragmatic principles are invariably indeterminate in their operation. In contrast, configurational accounts of 
definiteness, as proposed by Lyons (1086), would automatically exclude an indefinite reading of the possessive in (i).

8. Cross-language comparisons of possessive constructions are discussed by Zubizarreta (1987) and Giorgi and Longobardi (1991).

9. For a fuller discussion of these issues, see Taylor (to appear). 


\section{REFERENCES}

Anderson, Mona. 1978. NP pre-posing in noun phrases. Proceedings of the Eighth Annual Meeting of the North Eastern Linguistic Society, 12-21.

Brown, Roger. 1973. A First Language: The Early Stages. Cambridge, MA: Harvard University Press.

Chafe, Wallace. 1978. Cognitive constraints on information flow. In R.S. Tomlin (ed.), Coherence and Grounding in Discourse. Amsterdam: Benjamins, 21-51.

Chomsky, Noam. 1970. Remarks on nominalization. In R. Jacobs and P. Rosenbaum (eds.), Readings in English Transformational Grammar. Waltham, MA: Ginn and Co., 184-221.

Deane, Paul. 1987. English possessives, topicality, and the Silverstein hierarchy. Berkeley Linguistics Society 13, 65-76.

Fodor, J.A. 1983. Modularity of Mind. Cambridge, MA: MIT Press.

Giorgi, Alessandra and Giuseppe Longobardi. 1991. The Syntax of Noun Phrases: Configuration, Parameters and Empty Categories. Cambridge: Cambridge University Press.

Givón, Talmy. 1983. Topic continuity in discourse: An introduction. In T. Givón (ed.), Topic Continuity in Discourse: Quantitative Cross-Language Studies. Amsterdam: Benjamins.

Grimshaw, Jane. 1990. Argument Structure. Cambridge, MA: MIT Press.

Haegeman, Liliane. 1989. Be going to and will: A pragmatic account. Journal of Linguistics 25, 291-317.

Jaeggli, Oswaldo. 1986. Passive. Linguistic Inquiry 17, 587-622.

Kempson, Ruth. 1988. Logical form: The grammar cognition interface. Journal of Linguistics 24, 393-431. 
Langacker, Ronald. 1988. An overview of Cognitive Grammar. In B. Rudzka-Ostyn (ed.), Topics in Cognitive Linguistics. Amsterdam: Benjamins, 348.

Langacker, Ronald. 1991. Foundations of Cognitive Grammar. Vol. 2. Stanford: Stanford University Press.

Langacker, Ronald. 1992. The symbolic nature of cognitive grammar: The meaning of of and of of-periphrasis. In M. Pütz (ed.), Thirty Years of Linguistic Evolution: Studies in Honour of René Dirven on the Occasion of his Sixtieth Birthday. Amsterdam: Benjamins, 483-502.

Langacker, Ronald. To appear. Possession and possessive constructions.

Lyons, Christopher. 1986. On the origin of the Old French strong-weak possessive distinction. Transactions of the Philological Society 1986, 1-41.

Nikiforidou, Kiki. The meanings of the genitive: A case study in semantic structure and semantic change. Cognitive Linguistics 2, 149-205.

Quirk, R., S. Greenbaum, G. Leech, and J. Svartvik. 1985. A Comprehensive Grammar of the English Language. London: Longman.

Rappaport, Malka. 1983. On the nature of derived nominals. In L. Levin, M. Rappaport, and A. Zaenen (eds.), Papers in Lexical-Functional Grammar. Bloomington: Indiana University Linguistics Club, 113142.

Safir, Ken. 1987. The syntactic projection of lexical thematic structure. Natural Language and Linguistic Theory 5, 561-601.

Sinclair, Melinda, and Walter Winckler. 1991. Relevance Theory: Explaining Verbal Communication. SPIL PLUS 18, 1-97. 
Smith, Neil and Amahl Smith. 1988. A relevance-theoretic account of conditionals. In L.M. Hyman and C.N. Li (eds.), Language, Speech and Mind: Studies in Honour of Victoria A. Fromkin. London: Routledge, 322-353.

Sperber, Dan and Deirdre Wilson. 1986. Relevance: Communication and Cognition. Oxford: Blackwell.

Taylor, John. 1989. Possessive genitives in English. Linguistics 27, 663-686.

Taylor, John. 1991. Possessive genitives in English: A discourse perspective. South African Journal of Linguistics 9,59-63.

Taylor, John. To appear. 'Subjective' and 'objective' readings of possessor nominals.

Wilson, Deirdre and Dan Sperber. 1986. Pragmatics and modularity. Chicago Linguistic Society 22: Parasession on Pragmatics and Grammatical Theory, 67-84.

Zubizarreta, Maria Luisa. 1987. Levels of Representation in the Lexicon and in the Syntax. Dordrecht: Foris. 